\title{
GUERRAS HÍBRIDAS E FAKE NEWS: A ESCALADA DA AUTOVERDADE
}

\author{
GUERRAS HÍBRIDAS Y FAKE NEWS: LA ELEVACIÓN DE LA AUTO-VERDAD
}

Tiago de Moura SOEIRO¹, João Gabriel Nascimento de ARAÚJO², Francisco José Sobreira de MATOS³

Palavras-chave:

Guerras Hibridas;

Fake News;

Autoverdade.

Palabras-clave:

Guerras híbridas;

Fake News;

Auto-verdad.

\section{RESUMO}

Neste artigo objetivamos demonstrar como as Fake News são empregadas como um artifício das Guerras Híbridas funcionando como ataques precisos para a desestabilização de bases conceituais, políticas ou até mesmo enfraquecendo lideranças e Estados, fomentando distorções e/ou crises estruturais nos seus alvos. Para tanto, buscaremos compreender 0 conceito de Fake News, para em seguida traçarmos sua rota de relação com as guerras híbridas e por fim elencar os perigos da relação entre Fake News e processos de dominação social, deixando em evidência à clara intenção de grupos específicos ascender ao poder ao buscar o controle sobre aspectos intangíveis, tais como sociedade, ideologia, psicologia e informação.

\section{RESUMEN}

En este artículo pretendemos demostrar cómo se emplean las Fake News como dispositivo de Guerras Híbridas funcionando como ataques precisos para la desestabilización de bases conceptuales, políticas o incluso debilitando a líderes y estados, fomentando distorsiones y/o crisis estructurales en sus objetivos. Para eso, buscaremos entender el concepto de Fake News, luego se trazará su ruta de relación con las guerras híbridas y finalmente se enumeraran los peligros de la relación entre Fake News y los procesos de dominación social, destacando la clara intención de grupos específicos de ascender al poder cuando se busca el control sobre aspectos intangibles, como la sociedad, la ideología, la psicología y la información.

\footnotetext{
1 Doutor em Ciências Contábeis pela Universidade Federal de Pernambuco (UFPE) e Professor Adjunto da Faculdade de Economia, Administração e Contabilidade da Universidade Federal de Alagoas (FEAC-UFAL). E-mail: tiago.soeiro@feac.ufal.br

2 Mestre em Ciências Contábeis pela Universidade Federal de Pernambuco (UFPE) e Professor do Instituto Pernambucano de Ensino Superior (IPESU). E-mail: j_gabriel90@hotmail.com

3 Doutorando em Filosofia pela Universidade Federal de Pernambuco (UFPE). E-mail: franzeh@hotmail.com
} 


\section{INTRODUÇÃO}

Há hoje a disseminação massiva de uma ideia de "verdade maleável". Uma ideologia que desistiu da ideia de "verdade" no singular como o ponto final da investigação e, em vez disso, passa a ver a política, a ciência e assim por diante, como batalhas contínuas entre diferentes regimes de verdades à procura de uma agenda de dominação (Stenmark, Fuller, \& Zackariasson, 2018).

Essa condição não é algo propriamente novo. Em tempos passados, por exemplo, Sócrates e Platão travaram batalhas com sofistas relativistas confortáveis com o milieu cultural em que não existe uma clara distinção entre a persuasão e a demonstração (Doxa e epistheme). Por várias vezes existiram reviravoltas na história mudando o curso das autoridades estabelecidas que eram consideradas como ilegítimas (Descartes, 2008; Platão, 2004).

Entretanto, a modernidade trouxe consigo uma pluralidade sem precedentes de estilos de vida, pontos de vista, valores e consciência das diferenças. Porém, ao passo que se pluraliza, a pluralidade também relativiza (Berger \& Zijderveld, 2009). A relativização pode criar uma série de dissonâncias cognitivas e a "verdade maleável" torna-se atrativa para dissolver essas dissonâncias, por explicar afinal os conflitos aparentes não são conflitos reais (Berger \& Zijderveld, 2009; Zackariasson, 2018).

Assim, a dinâmica da relativização gera força real quando começamos a ver as diferenças entre nós e os outros como intratáveis, no sentido de que não vemos perspectivas de convergência e também reconhecemos a contingência mesmo de nossos próprios propósitos e práticas de fazer julgamentos e formar crenças (Hales, 2009).

Apesar de ser um conceito importante para compreender o mundo atual, a "verdade maleável", enseja pensar no que se pode chamar de "autoverdade", ou seja, algo que pode ser entendido como a valorização de uma verdade pessoal e autoproclamada a qual é revestida de um caráter extremo do conceito de subjetividade, levando a um potente individualismo, que atomiza a sociedade. Uma sociedade de indivíduos. $\mathrm{O}$ valor da verdade da autoverdade está no fato de dizer e não no que é dito. É este fenômeno do deslocamento de onde está o valor, do conteúdo do que é dito para o ato de dizer (Brum, 2018), que gera a identificação das pessoas/usuários com as ideologias veiculadas, ou seja, com uma verdade do indivíduo ou uma verdade determinada pelo "dizer tudo" da internet e grande negação fetichista.

Nesta perspectiva, o papel da(s) verdade(s), e mais precisamente, do debate sobre a(s) verdade(s) na nossa sociedade informacional é cada vez mais preponderante. Com o menor custo, a centralidade dos ecossistemas digitais e a difusão mais fácil de informações em torno das redes virtuais, observamos uma produção generalizada de informações que abriu as portas para a disseminação massiva de notícias, incluindo-se a de notícias falsas ou distorcidas, que ficaram popularmente conhecidas pela expressão Fake News, sendo essa um tipo de informação construída, sem necessariamente fazer jus ao contexto da verdade ou materialidade do dado, ou ainda, passar por crivo validador da veracidade da informação. 
A pretensa lacuna de poder legitimador ou validador do verdadeiro ou falso, abre margem para esse agente que desequilibra as relações de informação e desinformação: as Fake News. Entendemos por Fake News: os artigos e notícias intencional e comprovadamente falsos, que podem enganar os leitores a respeito do assunto apresentado (Allcott \& Gentzkow, 2017).

Neste contexto, as Fake News ganham importância exponencial por sua capacidade de alimentar e retroalimentar rapidamente ideologias no universo informacional da internet e mais precisamente nas redes sociais. As redes sociais configuram-se como este novo campo de disputa, onde toda discussão é envolvida em um imediatismo e volatilidade pretensamente validados pela ausência de poder validador.

As Fake News têm sido utilizadas como instrumento para uma nova espécie de guerra, as Guerras Híbridas (Korybko, 2015). De uma maneira geral, o termo híbrido é visto como uma combinação de meios convencionais e não-convencionais ou irregulares (Fernandes, 2016), e por isto a Guerra Híbrida é um "estilo de luta" característico da Era da Informação o qual baseia-se nas possibilidades oferecidas pela globalização e no livre acesso a tecnologias avançadas e realiza a combinação, em todas as áreas e fases, de ações convencionais e irregulares com os atos terroristas, propaganda e conexões com o crime organizado (Piella, 2018).

Esse tipo de abordagem busca trazer eficiência e efetividade para o atingir dos objetivos no contexto de uma sociedade informacional. Os altos custos das guerras tradicionais continuam paulatinamente sendo substituídos por exércitos informacionais, que municia indivíduos e grupos com informação construída para atingir determinado fim: desestabilização do inimigo elencado.

Em seu âmago, a Guerra Híbrida é o caos administrado. Ela começa com um vírus que subverte 0 sistema social do Estado alvo, e, se seus enxames e vanguardas pseudo-Guerra Não Convencional (Korybko, 2015). Assim, buscaremos compreender como as Fake News estão no centro do debate dessa nova forma de guerra e como este novo formato de guerra informacional interfere em processos de desestabilização de pessoas, entidades e governos chegando ao ponto de influenciar eventos históricos recentes e decisivos como a Primavera Árabe ou eleições de políticos de extrema direita em países importantes nos últimos anos.

Para tanto, buscaremos compreender o conceito de Fake News, para em seguida traçarmos sua rota de relação com as guerras híbridas e por fim elencar os perigos da relação entre Fake News e processos de dominação social e a fabricação de consensos em torno de ideias de transformação e/ou convulsão social.

\section{AS FAKE NEWS}

Apesar de o termo Fake News ter se popularizado mais recentemente, a literatura acadêmica em diversas áreas - a título de exemplo a economia, psicologia, ciências políticas e ciências da computação - já dava cobertura a este assunto (Allcott \& Gentzkow, 2017). Este assunto é debatido nas literaturas a respeito 
de: más interpretações políticas (Flynn, Nyhan, \& Reifler, 2017); como as novas informações afetam as crenças políticas (Berinsky, 2017; Nyhan, Reifler, Richey, \& Freed, 2014; Nyhan, Reifler, \& Ubel, 2013); como os rumores se propagam (Friggeri, Adamic, Eckles, \& Cheng, 2014), efeitos da exposição da mídia (Enikolopov, Petrova, \& Zhuravskaya, 2011; Gerber, Gimpel, Green, \& Shaw, 2011; Martin \& Yurukoglu, 2014; Spenkuch \& Toniatti, 2016); e segregação ideológica no consumo de notícias (Bakshy, Messing, \& Adamic, 2015; Flaxman, Goel, \& Rao, 2016; Spohr, 2017). Em se referindo diretamente a literatura sobre Fake News, esta apresenta como as notícias falsas se apropriam: da aparência de notícias reais; de como os sites são exibidos; como os artigos são escritos; e como as fotos incluem atribuições (Tandoc Jr, Lim, \& Ling, 2018).

Não obstante, há várias razões para pensar que as notícias falsas são de crescente importância e merecem atenção. Neste sentido, Allcott e Gentzkow (2017) nos forneceram quatro delas. Primeiro, as barreiras à entrada no setor de mídia caíram vertiginosamente, tanto porque agora é fácil configurar sites, quanto porque é fácil monetizar o conteúdo da web por meio de plataformas de publicidade. Como as preocupações com a reputação desencorajam os meios de comunicação de massa a reportar conscientemente histórias falsas, barreiras mais altas à entrada limitam as "reportagens falsas". Segundo, as mídias sociais são adequadas para a disseminação de notícias falsas e o uso das mídias sociais aumentou bastante: em 2016, os usuários ativos do Facebook por mês atingiram 1,8 bilhão e o Twitter, cerca de 400 milhões (Allcott \& Gentzkow, 2017). Terceiro, há um declínio contínuo da confiança nos meios de comunicação de massa quando se trata de relatar as notícias de maneira completa, precisa e justa. 0 declínio da confiança na grande mídia pode ser uma causa e uma consequência de notícias falsas ganharem mais força. Por fim, o quarto, refere-se ao aumento da polarização política em função dos sentimentos cada vez mais negativos que cada lado do espectro político mantém em relação ao outro. Isto pode afetar a probabilidade de cada lado acreditar em notícias falsas negativas sobre 0 outro.

As Fake News são provenientes de vários tipos de sites e redes sociais, onde indivíduos agem espontaneamente ou não, criando conteúdo baseados em crenças, com o intuito de sedimentar determinadas ideias. Alguns destes são criados inteiramente para divulgar artigos fabricados intencionalmente e enganosos. Nesses casos, esses sites possuem nomes que geralmente são escolhidos para se parecer com os de organizações legítimas de notícias. Outros sites satíricos contêm artigos que podem ser interpretados como factuais quando vistos fora de contexto. Outros sites, possuem uma mistura de artigos factuais, geralmente com uma tendência partidária, além de alguns artigos falsos. Os sites que fornecem notícias falsas tendem a ter vida curta, pois, geralmente, são descontinuados após cumprir seu propósito.

Parece haver duas motivações principais para fornecer notícias falsas (Allcott \& Gentzkow, 2017). 0 primeiro é pecuniário: artigos de notícias que se tornam virais nas mídias sociais podem gerar uma receita significativa de publicidade quando os usuários clicam no site original. Essa parece ter sido a principal motivação para a maioria dos produtores cujas identidades foram reveladas (Dewey, 2016; Subramanian, 
2017). A segunda motivação é conceitual/política: quando há uma tentativa de apresentar e ou comprovar uma ideia sem checagem, seja de forma intencional ou espontânea, dos fatos que tentam corroborar essa visão e sem necessariamente existir interconexão lógica entre premissas e conclusões. Alguns provedores de notícias falsas procuram adiantar candidatos que preferem (Townsend, 2016). Outros provedores de notícias falsas da direita dizem que se identificam como de esquerda, cujo interesse seria constranger os da direita, mostrando que eles circulariam credulamente histórias falsas (Dewey, 2016; Sydell, 2016).

Os Produtores de notícias baseadas em conceitos e ideologias disseminadas são empresas com duas características distintivas. Primeiro, eles não investem em relatórios precisos; portanto, seus sinais subjacentes não são correlacionados com o estado real. Segundo, eles não tentam construir uma reputação de qualidade a longo prazo, mas maximizam os lucros de curto prazo ao atrair cliques em um período inicial (Allcott \& Gentzkow, 2017). Desta forma há uma necessidade desse consumidor de informações digitais por notícias de forte impacto, de títulos chamativos e de revelações bombásticas, algo possivelmente relacionado a psiquê do humano. E dada a velocidade de chegada dessas informações, há uma dificuldade na distinção entre notícias reais e falsas.

Desta forma, com o alargamento do conceito e a exponenciação de sua importância, as Fake News assumem, hoje, um caráter ainda mais proeminente, o de desestabilização de bases conceituais, políticas ou até mesmo enfraquecendo lideranças e Estados. As Fake News unidas ao seu ecossistema de disseminação, as mídias sociais e tecnologias afins, funcionarão como ataque cirúrgico da parte agressora, fomentando desestabilizações e/ou crises nos seus alvos (Korybko, 2015). Isto mostra uma clara intenção de grupos específicos ascender ao poder e realizar a dominação social ao buscar o controle sobre aspectos intangíveis, tais como sociedade, ideologia, psicologia e informação, e além disso como a massa crítica é usada contra as autoridades e introduz 0 desafio que o movimento busca de confrontar publicamente 0 Estado e tentar derrubá-lo.

\section{GUERRAS HÍBRIDAS E SUAS AMEAÇAS}

Para que isso seja concretizado, esses grupos utilizam estratégias de guerras recentemente popularizadas e conhecidas como "Guerras Híbridas". O conceito de Guerra Híbrida continua sendo desenvolvido na literatura e é objeto de uma discussão complexa (Lima, 2018; Piella, 2018). Ainda não há um consenso de que a Guerra Híbrida seja um produto natural da adaptação das guerras irregulares (grosso modo, contrariamente aos costumes da guerra) e assimétrica (destinada a explorar as vulnerabilidades das forças regulares), bem como ausência de um denominador comum da combinação de meios, procedimentos e táticas convencionais e assimétricos (Piella, 2018).

Entretanto, o conceito inicialmente empregado pela Marinha norte-americana em 2002 para alertar sobre as táticas empregadas pela insurgência chechena contra o exército russo no período da Primeira 
Guerra Chechena (Nemeth, 2002) e apareceu pela primeira vez em um documento oficial três anos depois para explicar a combinação de duas ou mais ameaças do tipo tradicional, irregular, catastrófico ou perturbador (Defense, 2005).

No entanto, o seu conceito começa a ser popularizado a partir da publicação do artigo "A Guerra do Futuro: a Chegada do Conflito Híbrido" (Mattis \& Hoffman, 2005); da guerra entre Israel e o Hezbollah em 2006 (Cordesman, Sullivan, \& Sullivan, 2007); e da apresentação do ensaio "O Conflito no Século XXI: 0 Advento da Guerra Híbrida" (Hoffman, 2007). Porém, o conceito passou a ser tratado pela mídia não especializada e cruzou a fronteira do debate estratégico-militar a partir das intervenções de Moscou na Crimeia e na Ucrânia (Gerasimov, 2013). Piella (2018) destaca que os conflitos modernos possuem algumas características, por exemplo:

- Os atores envolvidos, que intervêm ou delegam diretamente suas ações a agentes ou procuradores domésticos, milicianos, guerrilheiros, terroristas, redes criminais ou contratados militares privados;

- Os meios utilizados, tais como armas simples usadas de novas maneiras, sistemas sofisticados transferidos pelos Estados, armas pesadas ou tecnologias de segurança com uso duplo disponível no mercado;

- As táticas utilizadas que contemplam as ações convencionais limitadas, atos terroristas, insurgência, operações cibernéticas, ocultação e engano ou propaganda em múltiplos canais;

- Multiplicadores usados, tais como os sistemas de posicionamento, inteligência de sinais, de fontes redes abertas e sociais, drones, automação de processos robóticos (RPA), comunicações para ataques ou ciberataques; e

- As fontes de financiamento que podem ser provenientes de atividades legais e criminais em estreita colaboração com o crime organizado.

Essas características tornam as novas guerras aparentemente muito diferentes daquelas onde havia uma declaração formal de guerra a qual impedia o surgimento de "áreas cinzentas" e onde os exércitos regulares pertencentes a um Estado-nação lutavam convencional e simetricamente em frentes claramente definidas, respeitando práticas e costumes de guerra aceitos pelos contendores e usando meios tecnologicamente avançados para a época (Piella, 2018).

Entretanto, há mais de dois mil anos, o estrategista militar da China antiga Sun Tzu já afirmava que a guerra indireta é uma das formas mais eficazes de combater um inimigo, uma vez que permite que um oponente derrote o adversário sem enfrentá-lo diretamente, economizando recursos que seriam despendidos em um confronto direto, além de atrasar o inimigo, colocando-o na defensiva e tornando-o mais vulnerável 
(Korybko, 2015). Isto ocorre em função da inexistência de uma disputa pareada, na qual não haveria a supremacia de uma parte sobre a outra, a parte inferior em termos bélicos utilizam-se de táticas assimétricas, pois, são forçados a adaptar e propor respostas que mitiguem a superioridade e explorem a fraquezas políticas, sociais, legais, morais, econômicas, demográficas ou militares de seus adversários aparentemente imbatíveis no campo convencional (Piella, 2018).

Lind et al. (1989) previram como seria a próxima geração de guerras, a qual definiram como guerras de quarta geração. $O$ viés econômico (de ser extremamente mais barata que a guerra convencional), e a responsabilização política (de não se saber com absoluta certeza de onde se começou o bombardeio informacional e o estímulo às revoluções coloridas) a responsabilidade seria diminuída, e o ônus da posição reduzido. A esse respeito, afirmaram que as operações psicológicas podem se tornar a arma operacional e estratégica dominante assumindo a forma de intervenção midiática/informativa, cujo principal alvo a atacar será 0 apoio da população do inimigo ao próprio governo e à guerra. Assim, as notícias televisionadas se tornarão uma arma operacional mais poderosa do que as divisões armadas. Lind et al. (1989) também previram com acerto, entre outras coisas, a implementação em massa de campanhas de informação contra um governo e que a "distinção entre 'civil' e 'militar' poderia desaparecer".

Ainda neste contexto, Hart (2008) discorre sobre a necessidade de aproximar-se do alvo por métodos inesperados e indiretos. Em outras palavras: na estratégia, o caminho mais longo tende a ser o caminho mais rápido para casa. Fica cada vez mais e mais claro que uma abordagem direta ao objeto mental, ou objetivo físico, de alguém, ao longo da 'linha de expectativa natural' do oponente, tende a produzir, e geralmente produz, resultados negativos, ao passo que a perturbação do equilíbrio psicológico e físico do inimigo é o prelúdio vital para uma tentativa bem-sucedida de derrubar o inimigo.

Assim, a Guerra Híbrida é caracterizada pela integração no tempo e no espaço de procedimentos convencionais com táticas típicas da guerra irregular (da propaganda, agitação, subversão, guerra de guerrilha e insurgência a atividades de guerra de informação, guerra legal ou operações cibernéticas), esta última combinada com atos terroristas e conexões com o crime organizado para financiamento, obtenção de apoio e assistência (Piella, 2018). Trata-se de uma estratégia que mistura diplomacia, política, mídia, ciberespaço e força militar para desestabilizar e minar um oponente. Nesse tipo de intervenções os agressores visam evitar retaliação ou responsabilização pelas suas ações, mas conseguindo seus objetivos iniciais de desestabilização e ou tomada ou consolidação de poder (Standish, 2018). A Figura 1 apresenta uma ilustração a respeito do conceito: 


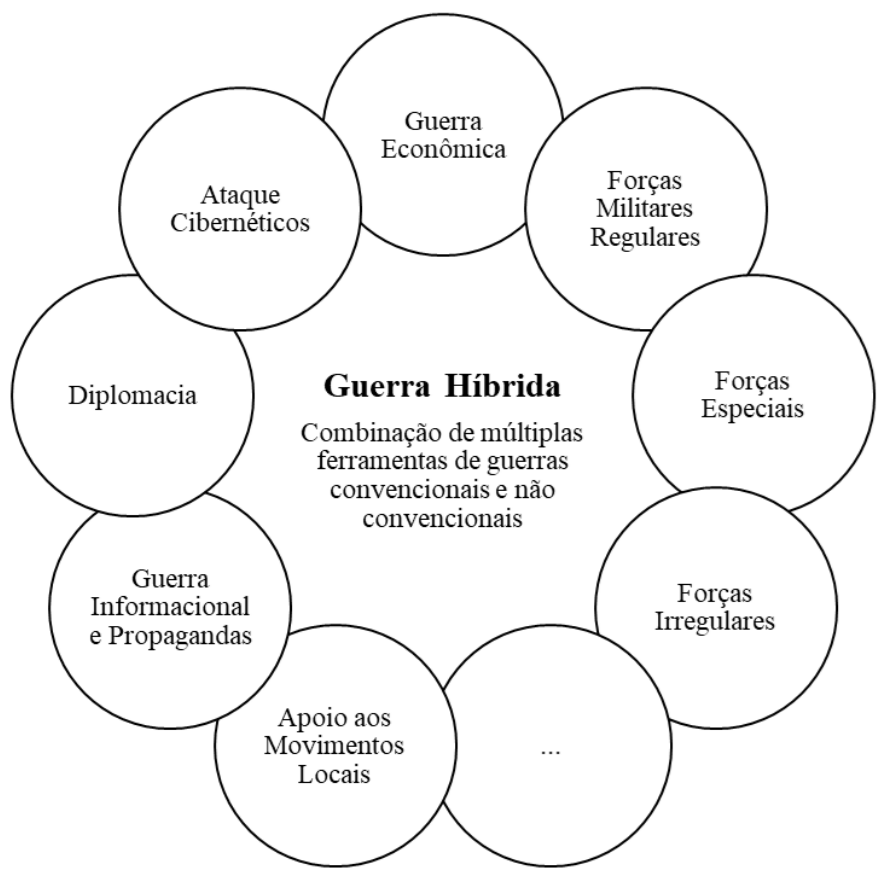

Figura 1 - Guerra Híbrida

Fonte: adaptado de Fernandes (2016)

Consequentemente, a tipologia, o status legal ou a organização do combatente podem ser fatores secundários na caracterização da ameaça híbrida, uma vez que o que é verdadeiramente representativo é sua capacidade de simultânea e efetivamente usar procedimentos e táticas convencionais, irregulares e terroristas (Piella, 2018). A esse recurso distintivo são adicionadas outras características secundárias (Murray \& Mansoor, 2012), tais como:

- $\quad$ uso de armas e materiais tecnologicamente avançados dos arsenais militares de um país e operados por um exército ou um ator não estatal e obtidos no mercado civil (drones, RPA, armas de precisão, mídia de inteligência, comunicações avançadas ou e-skills);

- A exploração efetiva de propaganda e informação on-line para espalhar sua mensagem, gerar narrativas que apoiam seus fins e corroem as opiniões públicas de seus oponentes;

- A organização interna flexível, adaptável e em rede;

- A falta normativa de definição e desprezo pelos usos e costumes da guerra tradicionalmente aceitos pela comunidade internacional; $\mathrm{e}$

- A combinação eficaz dos meios à sua disposição para infligir o máximo de dano físico e psicológico ao seu oponente.

A Guerra Híbrida é um conceito atraente e expressivamente poderoso por dois grandes motivos: mostra graficamente a crescente complexidade dos conflitos atuais e destaca o embaçamento das fronteiras 
entre pré-crise e crise; e guerra, entre forças regulares e irregulares ou entre táticas convencionais e assimétricas (Piella, 2018).

Por exemplo, campanhas de sabotagem geopolítica indireta sob as aparências de movimentos "pródemocracia" e/ou confrontos civis apoiados por fora não precisam derrubar um governo em si para dar certo tudo que precisa é fazer com que a sociedade se divida, e a incerteza em larga escala, arauto do caos social, faz 0 resto. Em outras palavras, basta semear o caos e criar forças centrípetas que por si só ameacem dilacerar uma sociedade alvo (Korybko, 2015).

Desta forma, a ideologia é, portanto, o ponto de partida de todas as Revoluções Coloridas, pois, ela representa uma forma de desenvolvimento oposta para uma sociedade doméstica e motiva segmentos simpatizantes da população a participar de manifestações tangíveis para exigir mudanças. Uma campanha de informação coercitiva que promove a ideologia desestabilizadora, pode realmente induzir a crer que suas ações são espontâneas e naturais e que representam o progresso inevitável que todas as regiões do mundo estão destinadas a viver mais cedo ou mais tarde (Korybko, 2015). Para ilustrar, se enquadram aqui, eventos que vão desde as revoluções coloridas do Leste Europeu, incluindo a Primavera Árabe, e até mesmo as eleições brasileiras de 2018, que levaram um governo de ultra direita ao poder (Costa, 2019).

\section{FAKE NEWS E DOMINAÇÃO SOCIAL}

É neste contexto que o uso das redes sociais e disseminação das Fake News visa promover "a desestabilização, a partir do financiamento e instrumentalização de atores sociais diversos em nome de interesses externos, de modo a promover golpes brandos" (Costa, 2019, p. 139). Assim, as Fake News são empregadas como um vírus, ou seja, uma abordagem indireta para contaminar as massas com ideias distorcidas por meio de um processo de produção e disseminação de ideias ou ideologias em que o seu conteúdo simbólico é (re)forçado através de uma matriz informacional, adquirindo assim a forma determinada e aceita pelo receptor. Isso quer dizer que as Fake News são criadas para (re)forçarem as ideias compatíveis com as crenças dos receptores e que é uma estratégia, metodologia ou um instrumento empregado pela Guerra híbrida.

Neste ponto, vale ressaltar que não temos a intenção de discutir conceitualmente o que é verdade, mas sim apresentar as Fake News como elemento influenciador das percepções sensoriais do mundo externo, fazendo-as identificar-se de tal modo com o "senso comum". Para ilustrar a pluralidade das possibilidades e formas que as Fake News se revestem, apresentamos no Quadro 2 uma síntese dos exemplos mais frequentes das formas observadas de Fake News. Neste respeito, o quadro sintetiza os tipos de Fake News, destacados na literatura. 
Quadro 2 - Tipos de Fake News

\begin{tabular}{|l|l|}
\hline \multicolumn{1}{|c|}{ Tipologia } & \multicolumn{1}{c|}{ Descrição } \\
\hline Sátiras & $\begin{array}{l}\text { Referem-se a veículos de notícias falsas, que geralmente usam humor ou exagero para } \\
\text { apresentar ao público atualizações de notícias. }\end{array}$ \\
\hline Paródias & $\begin{array}{l}\text { São utilizadas para fornecer comentários indiretos sobre os assuntos e brinca com o } \\
\text { absurdo dos problemas e os destaca criando histórias inteiramente fictícias. }\end{array}$ \\
\hline Fabricação de notícias & $\begin{array}{l}\text { Refere-se a artigos que não têm base fatual, mas são publicados no estilo de notícias } \\
\text { para criar legitimidade. }\end{array}$ \\
\hline $\begin{array}{l}\text { Manipulação de mídias } \\
\text { digitais }\end{array}$ & $\begin{array}{l}\text { Refere-se à manipulação de imagens, vídeos e áudios reais para criar uma narrativa } \\
\text { falsa. }\end{array}$ \\
\hline $\begin{array}{l}\text { Publicidade e Relações } \\
\text { Públicas }\end{array}$ & $\begin{array}{l}\text { Refere-se as notícias falsas veiculadas em materiais publicitários sob a forma de } \\
\text { reportagens/notícias genuínas ou comunicados de imprensa publicados. }\end{array}$ \\
\hline Propaganda & $\begin{array}{l}\text { Refere-se a notícias criadas por uma entidade política para influenciar as percepções } \\
\text { do público. }\end{array}$ \\
\hline
\end{tabular}

Fonte: adaptado de Tandoc Jr., Lim e Ling (2018).

A tipologia apresentada no Quadro 2 nos alerta para a fabricação artificial de notícias para que a manipulação da opinião pública seja mais eficiente. Estas ilustram as formas como as "fábricas de consenso" aproximam-se do público cooptando-os com base nas predisposições de seus perfis. Isto se deu em resposta à digitalização de notícias, pois, esta modificou a lógica das definições tradicionais de notícias e ofereceu espaço para não-jornalistas atingirem uma audiência de massa.

Neste sentido, as mídias sociais não apenas mudaram a distribuição de notícias, mas também desafiaram as crenças tradicionais de como as notícias deveriam parecer. Os sites de mídia social não são apenas marcados por ter um público em massa, mas também facilitam o rápido intercâmbio e a disseminação de informações, dentre elas, as Fake News. Desta forma, com as redes sociais essas notícias se espalham em forma de memes. Nesse sentido, a criação de memes contendo palavras, sons e imagens curtos e/ou simplórios, porém que impactam é uma das ferramentas do plano para transmitir as ideias que se tornarão parte integrante das próprias populações.

Desta forma, com a alta velocidade de disseminação dessas informações, cria-se uma onda de (des)informação nas redes sociais que convencem o público da "(falsa) veracidade" e "racionalidade" das ideias e informações apresentadas. Entretanto, cabe destacar que a desinformação na mídia não é um fenômeno novo. Ela ocorre desde o desenvolvimento dos primeiros sistemas de escrita (Marcus, 1992). Porém, como atualmente a desinformação encontrou nas plataformas on-line, principalmente as mídias sociais, um novo canal, pois, estas estão se tornando as principais fontes de notícias para um número crescente de pessoas (Tandoc Jr et al., 2018).

As notícias falsas ocultam-se sob um verniz de legitimidade, à medida que assumem alguma forma de credibilidade ao tentar parecer notícias reais. Além disso, indo além da simples aparência de um item de notícia, através do uso de bots de notícias, as notícias falsas imitam a onipresença das notícias ao criar uma 
rede de sites falsos. Este é um reconhecimento claro do lugar das notícias na sociedade, mas, ao se apropriar da credibilidade das notícias, as notícias falsas também podem minar a legitimidade do jornalismo, especialmente em um ambiente de mídia social, quando a fonte real de informação é frequentemente removida ou pelo menos percebida à distância (Kang, Bae, Zhang, \& Sundar, 2011).

Desta forma, as Fake News estão revestidas de com um manto ideológico, ou seja, o conjunto de ideias, pensamentos, doutrinas ou visões de mundo de um indivíduo ou de determinado grupo. Por isso, as Fake News podem mudar a energia de conflito dos atores individuais, uma vez que dependendo do código civilizacional/cultural e da melhor forma de penetrar nos anéis sociais (país, religião, vizinhança, trabalho e família) dos cidadãos alvo, as elas podem adaptar sua mensagem para criar seu próprio "vírus" personalizado a fim de conquistar novos adeptos. O vírus "contamina" os indivíduos trabalhando para modificar seu sentimento político, e a ideia é que, uma vez que encontre uma "vítima", esse indivíduo então "espalhará" ativamente suas ideias para outras pessoas, causando uma "epidemia política". Uma vez inseridas no repertório cultural, a dominação entra em ação. Sugerida pela própria ideia, seja ela ideológica, política ou social, os resultados são obtidos principalmente pela fabricação de consenso (Korybko, 2015). Cabe-se esclarecer que consideramos que as ideologias dominantes,

(...) são aquelas que tornam suas crenças naturais e autoevidentes - fazendo-as identificarse de tal modo com o "senso comum" de uma sociedade que ninguém sequer imaginaria como poderiam chegar a ser diferentes. Esse processo, que Pierre Bourdieu chama de doxa, leva a ideologia a criar um ajuste tão perfeito quanto possível entre ela e a realidade social, fechando assim a brecha na qual a alavanca da crítica poderia ser introduzida. A realidade social é redefinida pela ideologia para tornar-se coextensiva a ela, de tal maneira que se obstrui a verdade de que foi a realidade, de fato, que engendrou a ideologia. Ao contrário, ambas parecem ter sido espontaneamente geradas juntas, tão inseparáveis quanto carne e unha. 0 resultado, politicamente falando, é um círculo aparentemente vicioso: a ideologia só poderia ser transformada se a realidade fosse de tal forma que a permitisse ser objetificada; mas a ideologia processa a realidade de maneira a antecipar-se a essa possibilidade. As duas, portanto, ratificam uma à outra. Dessa perspectiva, uma ideologia dominante não tanto combate as ideias alternativas quanto as empurra para além das próprias fronteiras do imaginável (Bourdieu \& Eagleton, 1992, pp. 62-63).

O resultado, politicamente falando, é um círculo aparentemente vicioso: a ideologia só poderia ser transformada se a realidade fosse de tal forma que a permitisse ser objetificada, mas a ideologia processa a realidade de maneira a antecipar-se a essa possibilidade. As duas, portanto, ratificam uma à outra. Dessa perspectiva, uma ideologia dominante não só combate as ideias alternativas quanto as empurram para além das próprias fronteiras do imaginável (Bourdieu \& Eagleton, 1992).

Por conseguinte, por seu sucesso histórico, as lutas sociais e suas ideologias que clamam por modificações nas contradições internas deste modelo político-econômico hegemônico aparecem hoje como opostas à ideologia dominante - naturalizada e sedimentada como única via (Marx \& Engels, 1970), formas de luta "sem" causa material, como uma espécie de debater-se infantil, uma birra, ante a uma ordem dada 
pelos pais. Ou, então, ligadas eminentemente a bandeiras políticas muito específicas, que não conseguem aglutinar de forma coesa outras insatisfações e causas; mantendo difuso o jogo de forças empregado para 0 pensar destas relações e para a criação de uma possibilidade efetiva de modificação das condições estruturais de existência política.

\section{CONCLUSÕES}

O fenômeno das Fake News e informações não verificadas é um grande desafio contemporâneo, especialmente a mídia online em que o relativismo ético se tornou uma categoria geralmente aceita, e a verdade muitas vezes exposta à pressão dos valores comerciais (Polović, 2019). O compromisso com a verdade é certamente o mais antigo e estimado princípio ético da civilização, daí a ideia de verdades como valores positivos profundamente enraizados na filosofia da moralidade. A verdade é essencial para 0 processo democrático, pois, a democracia depende da informação do cidadão, ou dos meios de comunicação que incentivam o pensamento analítico.

No entanto, com a "transformação estrutural", promovida e moldada pelas mídias de massa que promoveram o aumento do consumo de massa e mercantilização da cultura, estamos sendo submetidos a um cotidiano dominado pela autoverdade que destrói a possibilidade da verdade e abre caminhos para um cotidiano de exceção (Brum, 2017).

Um dos sintomas do cotidiano de exceção que vivemos é a colonização de nossas mentes. Autoritaristas administram o horror dos dias, com suas violências e mentiras, de um modo que se tornam onipresentes. Como consequência, pequenos gestos de autocensura, silêncio e ausência se infiltram em nossas ações chegando ao ponto em que "o próprio pensamento se torna uma doença autoimune", pois, é principalmente assim que "o autoritarismo se infiltra, e vence antes mesmo de vencer" (Brum, 2019).

Narrar a história é sempre o primeiro ato de dominação. A história é uma construção coletiva, mas a autoverdade dos autoritários é que decide o que aconteceu e não apresenta bases de sustentação. Para evitar confrontação ataca-se a cultura e a educação. A cultura é a "palavra que nos apalavra", é o que "nos faz humanos." Por isso, precisamos recuperar a palavra como mediadora dos conflitos em todos os cantos onde houver gente. "Sem a mediação da palavra, se passa diretamente ao ato violento". Isso deve ser feito coletivamente, pois, o "único jeito de lutar pelo comum é criando o comum - em comum" (Brum, 2019).

Como consequência do que discorremos até então, fica claro que vários são os custos sociais em potencial desse fenômeno. Primeiro, as pessoas que confundem uma notícia falsa com uma legítima têm crenças menos precisas e ficam piores por esse motivo. Segundo, essas crenças menos precisas podem reduzir as externalidades sociais positivas, minando a capacidade do processo democrático. Terceiro, as pessoas também podem se tornar mais céticos em relação aos produtores de notícias legítimos, na medida em que se tornam difíceis de distinguir dos produtores de notícias falsas. Quarto, esses efeitos podem ser 
reforçados em equilíbrio pelas respostas do lado da oferta, ou seja, dos produtores de informação, uma vez que uma demanda reduzida por relatórios de alta precisão e viés baixo reduzirá os incentivos para investir em relatórios precisos e sinais de relatórios verdadeiros. Esses efeitos negativos são compensados com qualquer ganho de bem-estar resultante de consumidores que gostam de ler notícias falsas que sejam consistentes com as anteriores.

Desta forma, os constantes ataques à democracia provenientes das mudanças na tecnologia de mídia, tornam importante a checagem dos fatos, a fim de esclarecer a opinião pública sobre as notícias falsas espalhadas nas mídias sociais. No entanto, quando os fatos em preto-e-branco contradizem as alegações/informações produzidas pelo falante, os verificadores de fatos são capazes de ver apenas "mentiras" (Uscinski \& Butler, 2013).

Sendo assim, a maior defesa contra a Guerra Híbrida é o estabelecimento de salvaguardas civilizacionais que permitam que os cidadãos, de forma generalizada ou em larga escala, se sintam parte de "algo maior" e vejam em seu governo respeito e credibilidade. Desta forma, serão menos propensos a tomar parte em atividades subversivas contra ele (Korybko, 2015).

Por fim, cabe destacar que embora qualquer oponente estatal ou não estatal pareça demonstrar extremo realismo e saiba tirar proveito de seus pontos fortes e minimizar suas fraquezas, as sociedades ocidentais adotaram valores pós-modernos e pós-materialistas que impedem de ver o mundo como algo complexo e perigoso, onde poder, interesse e ambição podem provocar confrontos violentos e onde disputas internacionais podem ser resolvidas pacificamente de acordo com o direito internacional e diplomacia (Piella, 2018). Por esse motivo reluta-se em conceber o uso da força ou a ameaça de recorrer a ela como uma ferramenta de política externa para defender interesses ou soberania nacional (Guillem, 2014).

\section{REFERÊNCIAS}

Allcott, H., \& Gentzkow, M. (2017). Social media and Fake News in the 2016 election. Journal of Economic perspectives, 31(2), 211-236.

Bakshy, E., Messing, S., \& Adamic, L. A. (2015). Exposure to ideologically diverse news and opinion on Facebook. Science, 348(6239), 1130-1132.

Berger, P., \& Zijderveld, A. (2009). Society's Books of Note.

Berinsky, A. J. (2017). Rumors and health care reform: Experiments in political misinformation. British Journal of Political Science, 47(2), 241-262.

Bourdieu, P., \& Eagleton, T. (1992). Doxa and common life. New left review, 191(1), 111-121.
Brum, E. (2017, 29 May). Cotidiano de exceção: Como lutar pela democracia aprendendo sobre a tirania. $E I$ País. Retrieved from https://brasil.elpais.com/brasil/2017/05/29/opinion/1496 068623_644264.html

Brum, E. (2018, 16 Jul). Bolsonaro e a autoverdade: Como a valorização do ato de dizer, mais do que 0 conteúdo do que se diz, vai impactar a eleição no Brasil. El País. Retrieved from https://brasil.elpais.com/brasil/2018/07/16/politica/1531 751001_113905.html

Brum, E. (2019, 02 Aug). Doente de Brasil: Como resistir ao adoecimento num país (des)controlado pelo perverso da autoverdade. El País. Retrieved from https://brasil.elpais.com/brasil/2019/08/01/opinion/1564 
661044 448590.html?fbclid=IwAR3ERmgJ4tQX9gq2R uGzGkeMR1TEcGpX4FLansT5fYm2W2MZuqwYCi7PZ DA

Cordesman, A. H., Sullivan, W. D., \& Sullivan, G. (2007). Lessons of the 2006 Israeli-Hezbollah war (Vol. 29): CSIS.

Costa, S. K. (2019). Guerras híbridas, das revoluções coloridas aos golpes. Conjuntura Austral, 10(51), 139143.

Defense, U. S. D. o. (2005). The national defense strategy of the United States of America: Department of Defense.

Descartes, R. (2008). Meditations on first philosophy: With selections from the objections and replies: Oxford University Press.

Dewey, C. (2016). Facebook fake-news writer:'l think Donald Trump is in the White House because of me'. The Washington Post, 17.

Enikolopov, R., Petrova, M., \& Zhuravskaya, E. (2011). Media and political persuasion: Evidence from Russia. American Economic Review, 101(7), 3253-3285.

Fernandes, H. (2016). As novas guerras: $O$ desafio da guerra hibrida. Revista de Ciências Militares, 4(2), 1340.

Flaxman, S., Goel, S., \& Rao, J. M. (2016). Filter bubbles, echo chambers, and online news consumption. Public opinion quarterly, 80(S1), 298-320.

Flynn, D., Nyhan, B., \& Reifler, J. (2017). The nature and origins of misperceptions: Understanding false and unsupported beliefs about politics. Political Psychology, 38, 127-150.

Friggeri, A., Adamic, L., Eckles, D., \& Cheng, J. (2014). Rumor cascades. Paper presented at the Eighth International AAAI Conference on Weblogs and Social Media.

Gerasimov, V. (2013). Ценность науки в предвидении: Новые вызовы требуют переосмыслить формы и способы ведения боевых действий (O valor da ciência na previsão: novos desafios exigem repensar as formas e métodos de guerra). Retrieved from https://vpknews.ru/articles/14632

Gerber, A. S., Gimpel, J. G., Green, D. P., \& Shaw, D. R. (2011). How large and long-lasting are the persuasive effects of televised campaign ads? Results from a randomized field experiment. American political science review, 105(1), 135-150.
Guillem, C. P. (2014). La revolución militar posindustrial. Revista de Estudios Sociales (50), 113126.

Hales, S. D. (2009). Relativism and the Foundations of Philosophy: MIT Press.

Hoffman, F. G. (2007). Conflict in the 21st century: The rise of hybrid wars: Potomac Institute for Policy Studies Arlington.

Kang, H., Bae, K., Zhang, S., \& Sundar, S. S. (2011). Source cues in online news: Is the proximate source more powerful than distal sources? Journalism \& Mass Communication Quarterly, 88(4), 719-736.

Korybko, A. (2015). Hybrid Wars: the indirect adaptive approach to regime change. The People's Friendship University of Russia.

Lima, R. d. M. (2018). Guerras híbridas: o princípio de Heisenberg no pensamento estratégico e uma possivel alternativa. (Bacharelado Trabalho de Conclusão de Curso). Universidade de Brasília, Brasília.

Marcus, J. (1992). Mesoamerican writing systems: Propaganda, myth, and history in four ancient civilizations: Princeton University Press Princeton.

Martin, G. J., \& Yurukoglu, A. (2014). Bias in cable news: Real effects and polarization: National Bureau of Economic Research.

Marx, K., \& Engels, F. (1970). The german ideology (Vol. 1): International Publishers Co.

Mattis, J. N., \& Hoffman, F. (2005). Future warfare: The rise of hybrid wars. Proceedings-United States Naval Institute, 131(11), 18.

Murray, W., \& Mansoor, P. R. (2012). Hybrid warfare: fighting complex opponents from the ancient world to the present: Cambridge University Press.

Nemeth, W. J. (2002). Future war and Chechnya: a case for hybrid warfare. Monterey, California. Naval Postgraduate School,

Nyhan, B., Reifler, J., Richey, S., \& Freed, G. L. (2014). Effective messages in vaccine promotion: a randomized trial. Pediatrics, 133(4), e835-e842.

Nyhan, B., Reifler, J., \& Ubel, P. A. (2013). The hazards of correcting myths about health care reform. Medical care, 127-132.

Piella, G. C. (2018). GUERRAS HíBRIDAS. Cuando el contexto lo es todo. Ejército: de tierra español(927), 3844.

Platão. (2004). Gorgias. London/New York: Penguin Classics. 
Polović, J. (2019). " Lažne vijesti" kao politički alat sistemske krize liberalne demokracije i korporativnih medija. In medias res: časopis filozofije medija, 8(15), 2455-2470.

Spenkuch, J. L., \& Toniatti, D. (2016). Political advertising and election outcomes. Kilts Center for Marketing at Chicago Booth-Nielsen Dataset Paper Series, 1-046.

Spohr, D. (2017). Fake News and ideological polarization: Filter bubbles and selective exposure on social media. Business Information Review, 34(3), 150160.

Standish, R. (2018). Inside a European Center to Combat Russia's Hybrid Warfare. Foreign Policy, 18.

Stenmark, M., Fuller, S., \& Zackariasson, U. (2018). Relativism and Post-Truth in Contemporary Society: Springer.

Subramanian, S. (2017). Inside the Macedonian fakenews complex. Wired magazine, 15.

Sydell, L. (2016). We tracked down a fake-news creator in the suburbs. Here's what we learned. National Public Radio, 23.

Tandoc Jr, E. C., Lim, Z. W., \& Ling, R. (2018). Defining "Fake News" A typology of scholarly definitions. Digital journalism, 6(2), 137-153.

Townsend, T. (2016). Meet the Romanian Trump Fan behind a Major Fake News Site. Inc. In.

Uscinski, J. E., \& Butler, R. W. (2013). The epistemology of fact checking. Critical Review, 25(2), 162-180.

Zackariasson, U. (2018). Introduction: Engaging Relativism and Post-Truth. In M. Stenmark, S. Fuller, \& U. Zackariasson (Eds.), Relativism and Post-Truth in Contemporary Society: Springer.

Žižek, S. (2015). Primeiro como tragédia, depois como farsa: Boitempo Editorial. 